\title{
Prácticas de la larga duración y la extensión. Aproximaciones a Cuadernos de Lengua y Literatura de Mario Ortiz y Leñador de Mike Wilson
}

SANDRA CONTRERAS Universidad Nacional de Rosario - CONICET, Argentina / sandracontreras123@gmail.com

\section{Resumen}

Este artículo propone una lectura de los Cuadernos de lengua y literatura de Mario Ortiz y de Leñador de Mike Wilson como narrativas de larga duración en las que, no obstante sus evidentes diferencias en estilos y formatos, la escritura funciona como una práctica (material y terapéutica) indisociable de un encuentro radical con la materia, en tanto como una experiencia de constatación, y de un encuentro radical con las palabras, entendido como una huida del lenguaje hacia la manifestación de las cosas o hacia la extinción del yo.

Palabras clave: larga duración / extensión / Mario Ortiz / Mike Wilson

\section{Practices on long duration and expansion.}

Approaches to Cuadernos de Lengua y Literatura to Mario Ortiz and Leñador by Mike Wilson

Abstract

This paper proposes to read Cuadernos de lengua y literatura by Mario Ortiz and Leñador by Mike Wilson as two stances of what might be called «long duration narratives». Despite their evident differences in styles and formats, both works put their writing to use as a practice (material and therapeutic) that cannot be dissociated, on the one hand, from a radical encounter with matter, as an experience of verification, and, on the other, from a radical encounter with words, that is, the way in which language tends to vanish towards the manifestation of things or towards the extinction of the self.

Key words: long duration / expansion / Mario Ortiz / Mike Wilson

Recibido: 20/09/2019. Aceptado: 25/11/2020

Para citar este artículo: Contreras, S. (2020). Prácticas de la larga duración y la extensión. Aproximaciones a Cuadernos de Lengua y Literatura de Mario Ortiz y Leñador de Mike Wilson. El taco en la brea, 11 (diciembre-mayo) , 5-19. Santa Fe, Argentina: UNL. DOI: 10.14409/tb.v1i11.9150 
Hay escritores que en cierto momento de sus vidas convierten a la escritura, al acto físico de escribir, en una práctica: como un ejercicio, con su dinámica entre mano, posición del cuerpo, y útiles (lapiceras, tintas, cuadernos), como una gimnasia, no importa cuán fielmente observada, con sus horarios y rutinas. Por supuesto que la escritura como ejercicio espiritual es de larga tradición clásica: es la práctica entendida como «cuidado de sí», a la que Michel Foucault le dedicó sus últimos textos, y que remite a esa atención, puesta en los instrumentos y en las condiciones materiales de escritura, que saben tener los escritores que convierten el ejercicio cotidiano de escribir en arte de vida. Pero hay veces en que la adopción de esa práctica es más bien el medio para (volver a) poner en marcha la escritura después de lo que el escritor experimenta como un "quiebre», un paréntesis, en todo caso ese punto de inflexión que lo expone a las varias formas del vacío: la repetición, el agotamiento de la imaginación, la parálisis. Es lo que ocurre en La preparación de la novela, de Roland Barthes: el descubrimiento de la novela como una nueva práctica para escribir, como si no lo hubiera hecho jamás, después del hilo cortante del duelo. O lo que ocurre, otro ejemplo, en la novela de larga duración que es La novela luminosa: las rutinas que se da una y otra vez Mario Levrero (autoterapia grafológica, computadora, sillón, diario) para recuperar el entusiasmo después de aquella fuga del daimon que vive como una muerte espiritual.

A partir de su volumen $\mathrm{V}$ (2010), los Cuadernos de lengua y literatura de Mario Ortiz podrían ser leídos también como la práctica de un relato de larga duración en el que, por un lado, queda inscripta, como una hendidura temporal, una «feroz temporada de sequía» muy parecida a la agrafia, y en el que, por otro, la atención del poeta puesta en ciertas cosas en desuso - una cafetera oxidada, la carcaza de un televisor abandonado, un yuyo en una esquina sin embaldosar-las convierte en una serie de máquinas para volver a escribir. El pasaje de la poesía a la prosa es parte de esa transformación. La (in)capacidad para escribir no es de ningún modo un tópico en Leñador, de Mike Wilson (2013). Pero así como el umbral del relato es el abandono de todo, después de las batallas perdidas, y la huida a un territorio en el que todo un mundo nuevo se aprende en la práctica, así Wilson dirá públicamente, una y otra vez, que no fue el de la mera experimentación formal con la extensión el impulso de la novela sino, de un modo más simple y elemental, el de ir contra el agotamiento de su escritura: narrar, dice, ya no le daba nada, y encontró en el ejercicio de documentarse en manuales viejos y en el de redactar como si fuera una enciclopedia la posibilidad de practicar la escritura como un acto físico, a veces mecánico y hasta inconsciente (Wilson, 2017). El pasaje del ritmo narrativo a la expansión dilatada de textos descriptivos es parte del viraje. Una y otra experiencia, la de Mario Ortiz, la de Mike Wilson, es, para el escritor, terapéutica.

Pero lo que Leñador y los Cuadernos de lengua y literatura comparten, además, es el hecho de que ese proceso de reactivación de la escritura es indisociable de un encuentro radical con las cosas, lo que en ambas experiencias quiere decir, a su vez, un encuentro radical con las palabras. También el hecho de que el acto de escribir se presenta, vía unas particulares invocaciones a la filosofía de Wittgenstein, como una huida del lenguaje, cuando este es repetitivo y vacío, como una huida del lenguaje sobre el lenguaje para cavar en su lugar una salida: en dirección a la manifestación de las cosas o hacia la extinción del yo.

En este sentido, si bien es evidente que los estilos y formatos de los Cuadernos y de Leñador son diversos, casi extraños el uno al otro, también es cierto que ambos proyectos son testimonios del modo en que ciertas literaturas contemporáneas, que «contra la tentación de escribir libros» se encaran como «cuadernos de notas o registros de investigación» (Ortiz, 2013:10), transitan entre 
la certidumbre de una constatación (de que «las palabras existen», de que «las cosas son») y el ejercicio exploratorio de la (re)escritura. Testimonios también de la experiencia que tiene lugar en ese tránsito: una disposición ante las cosas (la cafetera o el bosque) que se convierte en una experiencia filológica con la materia como lugar de la posibilidad y con el entorno como pura exterioridad.

\section{I}

En la segunda parte del Volumen VII, que titula Tratado de fitolingüística y publica en 2013, Mario Ortiz (con este nombre se identifica el yo que escribe los cuadernos y así podemos designarlo) asocia la feroz temporada de sequía del invierno de 2009 en Bahía Blanca con el período de esterilidad literaria que en ese momento estaba atravesando. No se trataba, cuenta, de una falta de imaginación, sino de «la casi absoluta y literal incapacidad de escribir»: el papel en blanco, la birome en reposo, la imposibilidad de mínimas concordancias sintácticas (Ortiz, 2013:261). Lo que sigue del volumen tendrá por objeto exponer, mediante formulación de hipótesis, enumeración de etapas y descripción de resultados, el descubrimiento del cual el cuerpo del poeta y el texto mismo que estamos leyendo son testimonios: una mata de yuyos secos, sobre la que su mirada se depositaba cada vez que doblaba por la esquina sin embaldosar de Liniers y Castelar, comienza a producir efectos nerviosos en el cerebro, esto es, a proporcionar ideas, y luego a generar palabras, y enseguida a transformarse en escritura de trazo azul en el papel. Ortiz compone la escena en torno de una serie de condiciones materiales: la mañana, la hornalla azul, el mate, la hoja en blanco, la birome. Y concibe a su vez el proceso - la función establecida entre el yuyo y la mirada depositada sobre él - como una relación entre «partículas materiales» cuyos efectos son, también, de carácter material: es la planta, escribe el poeta, la que físicamente empieza a «ocupar un lugar en la página», reponiendo el espacio y el tiempo para que las ideas puedan desplegarse en la tinta azul. Ortiz —o el sujeto que observa, investiga, constata y anota — deduce a su vez que, en tanto apareció en «un momento en que todo tendía a la pulverización», las vibraciones que produce el yuyo de flor amarilla en el cuerpo del poeta («El tallo óptico transmite la vibración a mi cuerpo» —298—) son directamente curativas.

Ahora, la historia de la flor amarilla, o bien, y para decirlo en los términos del tratado que estamos leyendo, la exposición del caso de la planta medicinal y sus efectos sobre el sistema nervioso del escritor, es lo que cierra el libro editado en 2013 en el que, junto con el VII, Ortiz reúne el Volumen V, titulado Al pie de la letra y publicado originalmente en 2010, y el VI, titulado Crítica de la imaginación pura y publicado originalmente en 2011. Y sucede que los descubrimientos allí constatados (en la segunda parte del volumen VII), que corresponden a unos hechos ocurridos en el año 2009, se reinscriben, retrospectivamente, sobre las historias e investigaciones expuestas tanto en la primera parte del mismo volumen VII como en los volúmenes VI y V que fueron escritos, efectivamente y según el relato, después de esa experiencia. Quiero decir: es en el tramo final de los tres volúmenes reunidos en la edición de 2013 que el escritor expone el momento crítico —el punto de quiebre de la agrafia y su curación por medio de la atención puesta en una plantae inscribe ese punto de inflexión ("Lo crucial es esto», «Estaba escribiendo otra vez», —264-266-) como el origen de un relato, finalmente de larga duración, en el que, cada tanto, en cada recomienzo, se dispone a estudiar, como un caso de ciencia particular, la génesis material de su escritura y el proceso de producción material de las imágenes. 
El formato es, en general, de experimentación científica, o, mejor, el de la poesía como método para experimentar, materialmente, con lo real. En este sentido, si Tratado de fitolingüística, el volumen VII, se presenta como registro del descubrimiento experimentado en el cuerpo del poeta y en el cuerpo de la escritura («escribo e informo», «debo registrarlo todo», «anoto absolutamente todo»), Crítica de la imaginación pura, el volumen VI, es el cuerpo teórico y crítico de los cuadernos reunidos en 2013. No solo porque, una vez delimitado un campo de observación (el conjunto heterogéneo de materiales acumulados alrededor de unos corrales al fondo del jardín: rollos de alambre, postes y varillas, cacharros viejos, frascos, algunas cáscaras de naranja y papa picoteadas), procede derivando postulados unos de otros ( (1. Existen las cosas. 2. Existen las palabras. 3. Las palabras son cosas. 4. Las cosas son cosas») y condensa el principio básico de la teoría («Una función se descubre mirando con insistencia un objeto hasta que el ojo segrega un líquido caliente y aromático») sino porque demuestra, prueba, que es el acto de atención, en el sentido fuerte de una mirada intensa y de una concentración absoluta, la máquina generativa en el pensamiento-escritura de Mario Ortiz. Es el acto de atención el que convierte una cafetera agujereada en instrumento óptico para detectar y leer, en la chapa de una radio abandonada, una serie de inscripciones invisibles; o transforma, a través de la pregnancia de una imagen obsesiva, que insiste a lo largo de los años (el movimiento de la mano haciendo girar la manivela asociado al movimiento de la mano sobre el papel), un motor Ruston \& Hornsby, arrumbado como chatarra en un galpón, en máquina de escribir capaz de generar nuevas funciones y de ponerse a marchar a toda velocidad.

No son entonces yuyos devenidos plantas medicinales sino trastos convertidos en instrumentos y máquinas los elementos que ahora se proyectan como disparadores del texto poético. Su fin, sin embargo, es el mismo: «demostrar la dificultad del vacío» (Ortiz, 2013:187). De modo tal que, aun cuando su campo de observación sea el de los trastos y desperdicios, es evidente que la refuncionalización orticiana se funda menos en una ética del reciclaje como alteración y reasignación de valores (deshecho/útil, bajo/alto), que en una operación de supervivencia cuyo horizonte es siempre la muerte, la nada, la destrucción. El carácter práctico-terapéutico es, desde luego, inherente a esa imaginación material: «Entonces — concluye el poeta—, aquellos que afirman sentirse vacíos en su interior deberían tomar una lata vieja, elevarla hasta la altura de sus ojos, y dedicarle toda la atención de que sean capaces. Piensen en lo que ocurrió en estas páginas: objetos en desuso, condenados a lenta destrucción en la intemperie, han encontrado una posibilidad imaginaria (imaginaria porque es real) de sobrevida» (188). En este sentido, si en el Tratado de fitolingüística unos sujetos —el escritor y un amigo — se exponen al vacío de la aniquilación y una planta acude en auxilio, en Crítica de la imaginación pura unos objetos «exhiben su destrucción al aire libre como cadáveres insepultos» y la atención de la mirada, el acto fuerte de la atención, los rescata de la caída o del olvido que los «arrojaba definitivamente al rincón de los trastos inservibles» (161). Aniquilación y reactivación son entonces también, en Crítica de la imaginación pura, y en cada experimento del relato de larga duración, los términos entre los que transita la escritura. Y la máquina, en sus varios sentidos de acción, transformación, producción, e imaginación pura (189-191), es el recurso protagónico del cuaderno.

En este sentido es que los Cuadernos inscriben una y otra vez ese punto de quiebre que convierte, que ya ha convertido, la continuación de la serie en una periódica reanudación. En la primera parte del mismo Volumen VII, cuyo subtítulo es «Nelson (camina rumbo a la entropía, pero no es una pava ni un molinito)», Mario Ortiz, que, como lo habrá de contar en breve, ya comprobó 
en carne y escritura propias los efectos curativos de la planta, intenta «reiterar la experiencia de campo»: repetir, en el amigo hundido en el agujero negro de la catatonia, del insomnio y del silencio, su propia experiencia de recuperación del lenguaje. «Pedí prestada la birome y anoté "Planta" en un costado de la dirección de la clínica de internación. ¿Tendría sentido? ¿Daría los mismos resultados?» (Ortiz, 2013:251). La verificación de los resultados en el habla de Nelson quedará suspendida, o postergada, en el relato, pero los efectos del experimento (de su postulación como hipótesis) en el arte del escritor son decisivos. Dice Ortiz: «Hasta no hace mucho tiempo me conformaba con el silencio y por eso, como recomendaba Wittgenstein, preferí callarme ante una mesa de madera aglomerada que atravesaba el aire a bordo de una camioneta de mudanzas (cfr. volumen I)» (237). Se está refiriendo al Volumen I de la serie, publicado en el año 2000, allí donde el poeta filósofo creaba el espacio y lo llenaba de cosas y del devenir de las cosas: «no poesía/ no lengua/ no digas nada/ de lo que no se puede hablar/mejor/ ni mover el aire/ ni abrir ni cerrar las manos/ mejor no sufrir» (2000:16). Sin embargo, «algo fundamental ha cambiado»: «el hecho es que ahora - dice- ese silencio no me conforma porque existe un yuyo que me ha enseñado lo contrario» y este libro, el que está escribiendo ahora, en 2012, será «el último acto de resistencia frente a la mudez» (2013:238). Como se ve, la imaginación material de la fitolingüística tiene entonces unas consecuencias muy reales: una refutación de las premisas filosóficas iniciales y con ella un viraje decisivo en el programa y en la imaginación poética del escritor.

Sucede además que ese viraje se inscribe, o estaba ya inscripto, también en el comienzo mismo del Volumen V. Cronológicamente primero por su fecha de publicación, Al pie de la letra (2010) es la tercera variante de la teoría sobre las palabras y las cosas que Ortiz formula después de la sequía de la afasia. Es, podría decirse, su propedéutica. Las letras, que constituyen aquí el campo de observación (un muestrario de tipografías, un cuadernillo delgado y amarillento que Ortiz rescató de la casa paterna y tiene ahora sobre su escritorio), son cosas materiales: de ellas importa menos su carácter de signo que su cuerpo — su grosor, su tamaño, su diseño—, la mano que las traza, la fuerza con que el tipo se imprime en el papel, y hasta el volumen que adquieren en un juego de plástico para niños donde se vuelven aptas para el placer del tacto y también propicias al desgaste. Y son también objetos (después del trance de recuperación de la escritura, los objetos, en la imaginación material de Ortiz, serán siempre objetos de estudio y de representación) en tanto una mirada, en atención extrema, se deposita sobre ellas. Solo que esa mirada, principio generativo de la teoría sobre las palabras y las cosas, es una mirada que "gira en torno a un alfabeto» y que, en esa rotación, genera un relato pero también retorna a un cierto "punto de partida», allí donde «la topografía de las obsesiones se confunde con la de lo entrañable». Y en ese lugar, dice Ortiz, «cuando el ojo llega a ese punto exacto luego de incesantes circunvoluciones, imagina» (es decir, "crea imágenes») y entonces «el sujeto comienza a escribir en primera persona un relato posible» (Ortiz, 2013:19).

¿No se sitúa entonces en esta hipótesis el quiebre en relación con los cuadernos de poesía anteriores, los cuadernos I al IV publicados entre 2000 y 2010? ¿No está cifrado aquí, en el encuentro entrañable y vital de la mirada del escritor con el cuerpo de las letras, el pasaje de la poesía a la prosa en el relato de larga duración que son los cuadernos de Ortiz? Un pasaje que habría que pensar en términos de un tránsito - más bien un trance - en el que se implican, a su vez, aprendizajes radicales. Porque se trata de aprender todo de nuevo, como un "gigante torpe» aprendiendo las primeras letras en su vuelta imaginaria a la escuela, pero, a su vez, y esencialmente, de 
un aprendizaje histórico de las violencias y de las utopías que quedaron inscriptas, como en el de los hombres, en el cuerpo mismo de las tipografías. También, y sobre todo, de un aprendizaje político que se experimenta allí donde el yo se vuelve otro y lo entrañable se hace social:

Cuando llegamos a contestar estas preguntas [¿quién diseñó esa letra?], podemos comprobar que ese objeto que devolvía como un espejo nuestra propia imagen ahora se expande y deviene un hecho social, un espacio comunitario con su arquitectura y economía, con momentos de tráfico y quietud. Este es el momento en que me cruzo con mi propia mirada y atravieso el mundo de la interioridad. (2013:66)'

Las consideraciones finales del Tratado de fitolingüística, síntesis del método experimental de la imaginación material que vimos actuar a lo largo de los tres Cuadernos, insisten precisamente en señalar, como se señala con el índice, esa pulsión de supervivencia que funda la práctica de la imaginación material y que compromete, de un modo radical, el tránsito del yo hacia un volverse otro, o comunidad:

Lo que yo experimenté en ese entonces, durante la sequía de 2009, me permitió escribir más tarde un par de libros donde pude verificar un proceso similar operado en otros objetos: las letras que se perfilaban en un cuadernillo alargado y sobre una cornisa convocaron a la historia de los hombres y a las polillas de la noche: el agujerito de una cafetera oxidada dejó filtrar los rayos del sol y devino instrumento óptico que sigue oxidándose; la chatarra de un motor continúa siendo chatarra y, simultáneamente, máquina de escribir. Cada objeto y cada letra nos reclamaron un acto de atención. Solo entonces revelaron su propia historia, sus condiciones de uso y las circunstancias del abandono final. Establecieron nuevas funciones, propiedades de una física inédita, y precisamente por eso se alzan como espacio de resistencia contra los horrores de la aniquilación y el exterminio sin desviar, en ningún momento, su camino hacia la destrucción y el olvido.

Y ahora acabo de mostrarles lo que ocurrió en mi propio cuerpo: soy yo mismo y al mismo tiempo soy otro.

Por eso este libro es la conclusión eternamente provisoria. (2013:306)

El volumen VIII de los Cuadernos, que titula Conectores temporales y publica en 2014, introduce una decisiva variación en ese pliegue entre aniquilación y sobrevida que Ortiz articuló en la recuperación de la escritura, y en el que se sobreimprime, a su vez, el pasaje del poema a la prosa, y también el pliegue entre lo propio y lo otro, entre el yo y la comunidad.

La materia del volumen es el tiempo, lo que hiende la experiencia vital es la muerte del padre y el vaciamiento y la demolición de la casa familiar, y la pregunta que orienta ahora la escritura es la que interroga si, siquiera por un momento, «se puede volver a lo que fue». Recrear textos perdidos (las escrituras del padre, el primer cuento escrito en la juventud), como un modo de recuperar al menos un fragmento de «lo que se perdió» definitivamente, es la pulsión a la que Mario Ortiz se entrega, una vez más, en la forma de un experimento: «producir una página que coincida —palabra por palabra, línea por línea— con las de Mario Ortiz cuando tenía 17 años» (2014:50). El experimento puede parecer de inspiración menardiana (no se trata de reescribir esas páginas sino de recrearlas), solo que en lugar de imaginar su resolución por vía de la especulación (borgiana), esa imaginación involucra, de un modo más elemental, condiciones materiales de escritura (la 
misma ventana a través de la cual ver las últimas hojas de los ciruelos de la vereda iluminadas por el sol, el viejo escritorio de madera) y también el cuerpo del escritor (un «esfuerzo máximo de concentración, un esfuerzo de memoria absoluta que al reescribir cancele el presente», -91-). Las últimas treinta páginas del volumen, en las que, efectivamente, Ortiz vuelve a escribir el cuento de juventud (un relato del tipo de viajes a través de loops espacio-temporales), muestran que la documentación del experimento importa mucho más que la calidad del resultado, ${ }^{2}$ al mismo tiempo que exponen que esa prueba solo pudo sortearse después de haber pasado por la acción de transcribir, en las páginas anteriores, los textos de su padre, esto es, después de haber «sentido», «físicamente», mientras los tecleaba para este libro, el mismo entorno material y emocional en que habían sido escritos: el living, la frescura de los árboles, la luz que entraba por el ventanal, la plenitud. Y es en ese pasaje, que imagina físico, que la experiencia del cuaderno transita, una vez más, hacia la salida de sí: «Veo y toco y huelo [en la transcripción de los textos del padre] todo lo que pude encontrar en el fracaso de mi propia escritura ensimismada» (80).

Es en este sentido que el narcisismo, para el que despliega diversas figuras (la escritura ensimismada, el loop, la pesadilla de volver obsesivamente a lo mismo, el reflejo vacío, y también el temor a la repetición que lo asalta apenas recomienza la serie con el volumen VIII), es el nudo mismo del cuaderno: eso de lo que el escritor, a través de un "trabajo con la palabra», con el que espera dar «un cierre al ciclo de textos que comenzó en el cuaderno $V(. .$.$) y también a un período$ completo de [su] vida», quiere salir. «Volver a sí mismo para ser otro» (y esa insistencia en la vuelta es el único acto, intuye, que puede «enfrentar al Ángel de la Melancolía» que lo preside todo). O, lo que es lo mismo, «[r]eescribir hasta que el texto se abra a lo inaudito» (2014:10).

Por eso, todo el relato transita entre las figuras de lo literal (entre ellas la tautología y el eco enamorado de Narciso: "yo soy yo», «la casa fue la casa») y el espectáculo de las pequeñas metamorfosis. El instrumento es ahora el gabinete vacío del televisor Zenith que encontró al azar arrojado junto a un árbol y que, colocado sobre el tronco de madera frente a la parra (el montaje de la escenografía es siempre fundamental) en los Cuadernos, queda convertido en artefacto de doble función: fabulosa máquina «hiperrealista» (Ortiz la llama Homoscopio), que sirve para «ver de nuevo los objetos que uno tiene adelante», por ejemplo, «las hojas [que] tienen un verde intenso y que ya comienzan a formarse los racimos» (2014:22); y también conducto — ventana, abertura, hueco- que unos objetos atraviesan para transformarse, materialmente, en escritura: «Ahí están las esferitas absolutamente frescas, renovadas, jugosas: agarro la birome y escribo la palabra "uva". (...) Transformo esa pulpa azucarada en ondas azules que brotan de esta birome y se propagan sobre el papel» (66). Y esperen, ya "sentirán la dulzura de esa pulpa gelatinosa y fresca». ${ }^{3}$

Pero estas metamorfosis materiales, que el narrador imagina como realmente acontecidas sobre y a través de la página, son indisociables de una radical experiencia filológica. Es la indagación que Ortiz postula como imperiosa, histórica y políticamente, en el umbral del Volumen V, como método para extraer las potencias de sentido reservadas en las palabras, y que sigue practicando en los Cuadernos (ante la flor amarilla, el yuyo, el zapallo, el Napostá, el televisor) según intuiciones e interrogaciones inspiradas en el Cratilo de Platón. ¿En el nombre ya está la cosa? ¿En el nombre Napostá ya está el arroyo? (2013:48-51). «¿Las cosas están antes que las palabras? ¿Las palabras antes que las cosas? Los desperdicios, ¿seguirán llamándose televisor?» (2014:20). Entre esas derivas etimológicas, hay una que tiene resonancias especiales. Dice el narrador: «Materia es una palabra hermosa, viejo. ¿Sabés? Viene del latín, sí. Nació en el Imperio Romano, entre medio 
de los bosques donde vivían las hadas y los druidas pergeñaban sus hechizos. La materia pasó de boca en boca; con el correr de los siglos se fue deformando y en España se convirtió en la palabra madera» (132). Y precisamente, al modo de Giorgio Agamben (84) que, en su ensayo sobre el pasaje del libro a la pantalla, llama la atención sobre el sentido clásico del término «materia» (base del término «madera» y este a su vez de «libro») como lugar mismo de la posibilidad pura y de la virtualidad, que puede recibir o contener todas las formas (la página blanca, la tablilla para escribir sobre la cual todo puede ser escrito), esa «materia» a la que Mario Ortiz se aferra una y otra vez en la escritura de Conectores temporales («Me aferro a la materia» - 51, 131-) es la que se inscribe, con sus vetas y ondulaciones, en el escritorio de madera, enclave material indispensable para que el proceso físico de la escritura tenga, o vuelva a tener, lugar (2014:45). No, sin embargo, para que la palabra ensimismada se reproduzca de un modo obsesivo y paranoico, según «un movimiento infinito e inútil, repetitivo y vacío» (121), sino para abrirse, ahora que "ya es tiempo de cerrar un ciclo que comenzó hace treinta años sobre el viejo escritorio de madera en la habitación del fondo", al salto y a la transformación (89). Y, en efecto, de esto se trata, finalmente, en la experimentación temporal y en la deriva filológica del Cuaderno: de propiciar en la creación de la imagen una serie de metamorfosis, a la que Ortiz, con el Kafka de Informe para una academia, llama también «salidas»; de propiciar en la práctica de la escritura el salto final, «ahí donde terminan las ideas/ donde solo hay un mecerse de pétalos/y brillos» (137); de romper el círculo del eterno retorno narcisista hacia la evidencia de las cosas, hacia la «extinción del yo»:

El texto ya no vuelve sobre sí mismo porque al fin atravesó su propio reflejo.

Está por dar el último salto.

Despojarse,

aceptar la destrucción

perder todas y cada una de las cosas, de los órganos, de los seres que amamos hasta quedarse desnudo o menos que desnudo

menos que nada.

Solo entonces se revelan en toda su intensidad los reflejos del atardecer,

las uvas,

las estrellas, las constelaciones. (135)

\section{II}

Lo que Mario Ortiz imagina en el Volumen VIII como un salto final hacia fuera del lenguaje ensimismado, es de algún modo equivalente a aquello que Mike Wilson plantea en términos de una huida de los espejismos del lenguaje en dirección a la certeza de las cosas y que practica - porque la escritura también se encara aquí como una práctica - en su novela Leñador, publicada en 2013. No necesariamente porque sitúe a su personaje en los bosques del Yukón, huyendo de su mundo, sino porque la huida del lenguaje, de sus derivas inútiles o inconducentes, de su carácter paródico, se ensaya a través de la exploración misma en el lenguaje. El diálogo se entabla así no tanto, como tendemos a pensar de inmediato, con Walden, de Henry Thoreau, sino más bien con 
la filosofía del lenguaje de Wittgenstein, más propiamente, con la lectura que Wilson, en la línea de interpretaciones conocida como The New Wittgenstein, hace del Tratado Lógico-filosófico y de las Investigaciones Filosóficas, y a la que él mismo dedica el libro Wittgenstein yel sentido tácito de las cosas, publicado en 2014. Filosofar, dice Wilson leyendo a Wittgenstein, implica una contorsión del lenguaje sobre el lenguaje, que aleja finalmente del sentido, el cual, por el contrario, se manifiesta, inexpresable, en el acto pre-reflexivo y en el entendimiento tácito de las cosas (2014:47, 71). Y si liberarnos de la necesidad de explicarlo todo tiene efectos terapéuticos, en el sentido de aliviarnos de una búsqueda inane (25), el recurso a la descripción enciclopédica podría estar funcionando en Leñador como una herramienta eficaz para dar forma a esa articulación, medular en la imaginación de Wilson, entre certeza (de las cosas) y alivio (de la especulación).

Así, los fragmentos narrativos que van escandiendo las entradas descriptivas, esas que ocupan masivamente la novela, abundan en observaciones moldeadas, claramente, en esta filosofía. Por ejemplo: «quiero pensar que en lugares como los bosques, en este, en el de las sequoias, la realidad de las cosas retorna, que despierto del estupor y que las cosas se hacen inconfundibles. Que al permanecer en lugares así, los espejismos del lenguaje se disuelven y la realidad se vuelve palpable» (Wilson, 2013:124). O: «La vida en el Yukón es difícil, cruda, pero hay algo que subyace, algo que le da serenidad al viejo leñador [noruego]. Una certeza que no se transmite, no se articula, que no tiene que ver con dogmas ni filosofías, una certidumbre que él ve porque la ha descubierto por sí solo, sin buscarla» (139). Etcétera. Son numerosas y le dan un color inconfundible al relato, un tono como punto de vista sobre el mundo.

Más interesante, sin embargo, es la forma en que en el lenguaje mismo la novela produce un efecto de certidumbre, de constatación. No me refiero aquí al procedimiento más notable y evidente, el de desplegar, al modo de una enciclopedia o de un manual, las más de ochenta entradas entre descriptivas e instructivas sobre el mundo de los leñadores (las herramientas, las técnicas, las costumbres, el clima, etc.), sino a cierta atmósfera de haiku que cada tanto emerge, precisa y paradójicamente, en los fragmentos narrativos que las escanden. Son varios pasajes también, y en general convocan, para decirlo en términos de Roland Barthes, la aparición de un incidente, un registro breve, y en general tópicos como los del tiempo y las estaciones. Por ejemplo: «En el verano llegan las luciérnagas. (...) A veces varias se iluminan a la vez y lanzan una penumbra amarillenta sobre el suelo del bosque, las sombras se alargan» (Wilson, 2013:217). La hipótesis podría predisponernos a leer esas notaciones como formas de propiciar «el desvanecimiento del lenguaje, que se da vuelta, huye y desaparece, dejando al desnudo lo que dice en beneficio de una certeza de realidad» (Barthes:118)».4 Pero si propongo leer en esos pasajes la resonancia del haiku barthesiano es, sobre todo, porque en esas emergencias siempre está implicado el sujeto que escribe: es su testigo. Y porque la inscripción del entorno en el sujeto (el modo según el cual el sujeto que escribe se constituye en su vínculo con el entorno) es crucial en la novela. «Un haiku, —dice Barthes— es lo que sobreviene en la medida en que rodea al sujeto, quien sin embargo no existe, no puede llamarse sujeto, sino por ese entorno fugaz y móvil»; también: «La notación del haiku es absolutamente subjetiva; el referente es el circunstante: el cuerpo tórpido del enunciador que se dice mediante su entorno» (96).

No habría que pasar por alto, en este sentido, que de la página 300 en adelante, cuando el protagonista enuncia el deseo de ir en busca de la mujer con la que se cruzó en el campamento, comienza su viaje de regreso. $O$, mejor, su salida del bosque: la otra huida. Porque si la huida es el umbral 
primero de la novela ( Me fui del país, buscando alejarme de todo, de la oscuridad, del pasado, de la claustrofobia, necesitaba respirar. (...) Hui hasta llegar a los bosques de Yukón»), en la página $316 \mathrm{el}$ yo que escribe dice: «La verdad era que deseaba escaparme de ese encierro y encontrar mi lugar fuera de mí». Y más adelante: «Siento que me he alejado, de verdad alejado. (...) Mis pisadas siguen siendo el sonido más fuerte, no dejo de escucharlas, a veces trato de ignorar el ruido de mis pies, pero no puedo. Quisiera poder, así dejarme atrás, salir, de verdad salir» (Wilson, 2013:330). Entiendo que en esa salida final (que ocupa una tercera parte de la novela, de su extensión) se cifra, por segunda vez, la pulsión de quien quiere huir de las trampas circulares del lenguaje (de lo que Ortiz vive en los Cuadernos como la pesadilla del retorno a lo mismo, o de lo que Wilson concibe en Leñador como esas falacias y «artificios que nublan la experiencia»), sencillamente porque esa salida solo tiene lugar cuando algo le ocurre a la escritura: el retorno del poema en el salto final del Cuaderno VIII podría ser una de esas formas; la notoria modificación en la organización de las entradas podría ser una señal en la novela. Me refiero en particular a las dos últimas entradas, previas a la impresionante frase final de treinta páginas, y que corresponden a (¿los conceptos? ¿las palabras? ¿las cosas?) «Entorno» $\mathrm{y}$ «Bosque». No solo son particularmente extensas (a diferencia del resto de las entradas, organizadas en dos o tres ítems, estas ocupan cada una seis páginas completas, ininterrumpidas, dedicadas únicamente a ese vocablo) sino que además en ellas cobra espesor una elaboración conceptual-narrativa en la que el sujeto que escribe, que había encontrado en el registro descriptivo, despojado y directo, una forma pre-reflexiva apta para hacer emerger la certidumbre de las cosas, ahora se embarca en extensas y por cierto complejas, y hasta sesudas, operaciones de interpretación, de intelección, de deconstrucción. Definiciones densas, deducciones, razonamientos:

Para aquel que no ha logrado sensibilizar los sentidos y el cuerpo a dicho entorno, el territorio es un espacio foráneo en el cual uno se subjetiviza ante el paisaje y por ende se individualiza en relieve contra el bosque. Esta disposición crea un sujeto apartado del territorio, en él pero no parte de él. Esta oposición entre sujeto y Naturaleza resulta en una relación tensa entre ambas partes. Cuando los leñadores navajos que afirmaron que el hombre blanco no sabía descifrar el territorio, sospecho que se referían a eso: al no saber ser parte de este, integrarse, dejar que el paisaje te asimile y no pararse en oposición a él. Para el hombre blanco, la Naturaleza suele ser el enemigo, algo contra lo cual luchar para así lograr subordinarla y dominarla. El fin de esta mirada es posicionarse arriba en la cúspide de una jerarquía inventada. Esa misma disposición jerárquica es la que irónicamente lleva a muchos a perecer en el territorio. En dicho sentido, intento desordenar y desmantelar semejante mirada hacia el entorno y comprender el lugar y la función que uno cumple al pasar a ser parte del territorio. A veces siento que es un estado casi hipnótico, pero en realidad es lucidez, y lo que dejo en el camino es la somnolencia, la conciencia aturdida por los ruidos de la memoria. (430-431).

¿Significan estas importantes entradas conceptuales el fracaso, o la contradicción, de una escritura que buscaba explorar las vías pre-reflexivas del lenguaje para constatar, sin intermediaciones, que "las cosas son»? Diría que no, que en todo caso esa falla es en Leñador la huella visible de un pliegue entre notación e interpretación, entre despojamiento y conceptualización, entre notación y novela, entre síntesis (o laconismo) y extensión.

La última frase, esa frase única de treinta páginas, vuelve a dar otra vuelta en el cambio de ritmo, y de densidad, de la escritura. Esa frase es sin dudas el clímax de la búsqueda de la novela, de 
su premisa filosófica. Si en el comienzo el protagonista se definió en la huida pero también en la disposición al aprendizaje (aquel párrafo inicial continuaba: «Me recibieron en un campamento de leñadores. [...] Eran hombres rudos. Me otorgaron un hacha, filo de acero. El cabo era de olmo liso, la madera oscurecida por años de uso. Pesaba más de lo que aparentaba. Aprendí cosas»), en el final lo encontramos ante el árbol, «disponiéndose ante el árbol», y en la acción de hachar. Como si la novela, una vez más poniendo a prueba su premisa filosófica («Confirmamos la verdad y la certeza del hacha al hachar y no al articular juegos de lenguaje que buscan elucidar la ontología del hacha», —2014:71—), pusiera en escena el tránsito de la definición de la cosa a su instrumentación en acto. Por supuesto que estamos y seguimos estando aquí en el orden de la representación: es obvio que esa acción está representada en el lenguaje. Pero la desmesurada descomposición de la acción de talar en sus más mínimos detalles y, sobre todo, la repetición y expansión del núcleo de imágenes que condensan el momento del golpe, hacen de la frase misma, de su ritmo y de su ritornello, una acción:

el filo hace contacto con la corteza, el mundo comienza a frenarse, las capas corrugadas de la corteza se abren ante la hoja, pequeñas astillas y fragmentos oscuros florecen y vuelan en varias direcciones, cierro los ojos para protegerlos de las astillas, atraviesa la corteza con facilidad y encuentra su destino, la superficie externa de la albura es dura y detiene la hoja, el estruendo del impacto se hace escuchar, es un sonido grave, opaco, pero fuerte, la onda sonora se expande por el territorio, el sonido dice cosas, muchas cosas, la especie del árbol, su tamaño, su diámetro, la sequedad de la madera, la oxidación de las agujas, la proximidad de su muerte, la necesidad del hachero, y en un instante el árbol retribuye la violencia del golpe, la energía regresa a mí, parte en la hoja de acero, vibra en el empalme y... (2013:471, subrayados míos)

Y cuando la frase vuelve con cada golpe, en torno de ese núcleo poético se despliega cada vez un racconto errático pero estructurado (es el arte de la enumeración) de las distintas escenas e imágenes del relato: «el sonido dice cosas, muchas cosas, la última tala del leñador, su pulso, la extensión de sus brazos, la lejanía del campamento, la hondura del volcán, las miradas de los búhos (...) las palabras del haitiano, los números dibujados en el suelo, la certeza del territorio, la proximidad de su muerte, la necesidad del hachero...» (2013:492, subrayados míos). Así una y otra vez hasta la transición de la primera a la tercera persona, hasta la identificación con el entorno a través de la disolución del yo:

y en un instante el árbol retribuye la energía del golpe, la energía regresa a él, parte en la hoja de acero, vibra en el empalme y desciende por el cabo, sube por sus antebrazos, golpea sus hombros, se acumula en sus omóplatos (...) y escucha cómo el interior del tronco pálido comienza a ceder bajo su propio peso (...) y la copa del árbol comienza a temblar y balancearse, el pino se aleja del leñador, el tronco cae hacia el oriente, la copa se mece y desciende, como si el árbol inclinara la cabeza, como si se despidiera con una reverencia, se lleva el aire al tumbarse, el impacto es extrañamente mudo, se escucha en el pecho, en las cosas y en el bosque, el suelo se alza, las agujas secas se elevan, las aves toman vuelo, una ráfaga y calma. (492)

En este sentido, sería interesante pensar, como lo sugiere el mismo Wilson, la extensión de la novela como efecto de la duración necesaria para dar lugar a la acumulación de la experiencia en el camino hacia el aprendizaje de las cosas: del «hacha» de la primera entrada a la acción de ha- 
char del narrador. ${ }^{5}$ Pero si es posible admitir esta hipótesis del lado de la práctica de la escritura, tal vez haya que pensar la cuestión, también, del lado de la lectura. Y no por la extensión en sí de la novela sino por la práctica de lectura a la que nos enfrenta, y que es probablemente su apuesta más radical. Porque: ¿cómo se lee Leñador? Si admitimos que, en función de la forma que adopta, en gran parte el libro se compone al modo de una enciclopedia o de un manual, ¿se lee una enciclopedia completa y de corrido? En todo caso: ¿leemos efectivamente todas y cada una de las entradas de Leñador? ¿una después de la otra, como si fuera una novela? En la novela hay dos escenas clave, en las que el narrador y protagonista lee, como un libro, un viejo almanaque agrícola que encontró en el campamento, y en ambas se trata de la acción de la lectura como la adopción de un «como si»y también como una práctica, un ejercicio. En la primera leemos:

En el margen de la octava página del almanaque agrícola, alguien escribió Esto es arte. Abandoné la lectura, me quedé mirando la frase manuscrita, tratando de imaginar qué habría impulsado al autor de esas tres palabras. Decidí que se refería al almanaque mismo. Pero no en el sentido de objeto estético per se, sino más bien por la anacronía del compendio.

Los almanaques pertenecen a otro tiempo y otra mentalidad, así como las guías telefónicas o los manuales de niños exploradores. Son libros sin ánimo creativo, escritos al servicio de la función pragmática. Sin embargo, me surge la duda de qué son cuando pierden su utilidad. Un manual de instrucciones que detalla la manutención de motores a vapor, ¿sigue siendo un manual aun cuando ya nadie utiliza motores a vapor? Puede ser. O quizás sea otra cosa, quizás a partir de la obsolescencia de un texto, este se vuelva literatura, se vuelva arte. El manual, el almanaque, la guía, pasa a ser novela, una novela dotada de una honestidad brutal, sin artificio, sin pretensiones ni ambiciones literarias, sin ánimo de vanguardia ni de experimentación, simplemente un texto libre de espejismos.

La siguiente noche disfruté más de la lectura del registro agrícola. Como si se me hubiese divulgado un secreto que los demás ignoran. (2013:95)

Como se ve, se trata no solo de la postulación de la obsolescencia del libro (la inutilidad de almanaques viejos o manuales anacrónicos) como condición para su conversión en literatura y en arte, sino también, y sobre todo, de la postulación de la novela como un modo de leer. ${ }^{6}$

En la segunda escena, en la que después de un día de trabajo arduo se sienta a leer otra vez, el narrador dice:

Después me senté junto a una ventana y leí el almanaque agrícola. Era una tabla que ocupaba varias páginas en la que se detallaban las toneladas de trigo cosechadas durante un período de diez años. De dónde provenían las espigas, la calidad de los granos, el destino de los cargamentos y la asignación proporcional del grano. Leí las columnas de cifras sin presura y tomé peso del significado de los números, de su manifestación en el contexto. Lo leí entero, lo entendí y me sentí bien. (2013:247)

Algo de esto ocurre, creo, cuando el detenimiento y la extraña concentración que nos propone la lectura de corrido de una enciclopedia nos induce a una suerte de hipnosis, también a cierto alivio, mental y corporal.

Y probablemente pueda situarse aquí el horizonte último de la larga duración. Porque, como los Cuadernos de lengua y literatura, que Mario Ortiz describe como periódicos ejercicios de 
lecto-escritura, Leñador pertenece a esa familia de relatos que, mientras hacen de la escritura una práctica para dar el salto a lo real (hacia la trascendencia del entorno diría Wilson, hasta la perforación de la materia diría Ortiz), inducen a reinventar la práctica de la lectura.

\section{Notas}

1 El cruce entre el aprendizaje, que tiene lugar en la revisión histórica y política de las tipografías, y el devenir comunidad del sujeto que aprende y escribe, parece quedar inscripto en el título de la segunda parte del volumen V: «Los maestros tipógrafos (Los otros)».

2 Dice el narrador: «Me siento extremadamente raro escribiendo un cuento. No soy un narrador y pienso que posiblemente encuentren este relato mal escrito, pesado, poco original. De hecho es así. Pero insisto: esto no es un cuento sino el recuerdo de un cuento, su reescritura, o mejor dicho, su recreación» (Ortiz, 2014:91).

3 Aquí se lee, dice Ana Porrúa, el proceso de la imagen que nos sitúa ante el tiempo, ese proceso de los conductos que unen y transforman, proceso que en la obra de Ortiz adviene, justamente, en el movimiento (5).

4 Como sabemos, Barthes asocia esta particular forma de entender el haiku con lo que define, en su práctica de «lectura patética» de la novela, como un «momento de verdad»: no como develamiento de un sentido oculto sino, por el contrario, como «surgimiento de lo ininterpretable, del último grado del sentido, después de lo cual no hay nada que decir» (162). A esa emergencia del momento de verdad, que corresponde al pasaje de la interpretación (del sistema de signos) a lo intratable (de la realidad), al pasaje del realismo a lo Real, Barthes la llama también epifanía o manifestación; y el sujeto que está allí para atestiguarlo, dice, es siempre el artista o el escritor (155).

5 «La extensión de la novela — dice Wilson— no fue premeditada, aunque al ir avanzando me di cuenta de que iba a alargarse; no era algo que me cuestionara sino que había algo en la acumulación de la experiencia del personaje que, solamente así, se iba a abrir la posibilidad de llegar al final de la novela, avanzar hasta que las cosas se le hacían manifiestas» (2017).

6 También podríamos preguntar: ¿quién y cómo escribe las entradas de Leñador? Wilson (2017) cuenta que leyó muchos textos, sobre todo viejos y hasta obsoletos, que lo que iba escribiendo era lo que le iba quedando en la memoria (razón por la cual, cuenta, hay también en la novela muchas cosas apócrifas), pero que lo que le interesaba era «el efecto que produce escribir y leer en esa clave, el efecto acumulativo y tácito de esa clase de texto no-narrativo donde la parodia no tiene cabida». Es decir: ningún juego con la verdad o falsedad de la información; solo la práctica de escribir. Lo cierto es que, en cuanto a la forma que adoptan o que se dan, podríamos pensar estas entradas como si fueran las transcripciones de alguien que está leyendo, que está aprendiendo, para instruirse mejor sobre el mundo en que está incursionado. O también, podríamos leer el compendio como si estuviera escrito al modo de un manual, en el cual quien redacta las instrucciones se implica y las rubrica a su vez como un ejemplo: «observé», «probé», «aprendí».

\section{Referencias bibliográficas}

Barthes, R. (2005). La preparación de la novela. Notas de cursos y seminarios en el Collège de France, 19781979 y 1979-1980. Buenos Aires: Siglo XXI.

Agamben, G. (2014). Del libro a la pantalla. Antes y después del libro. El fuego y el relato. México: Editorial Sexto Piso, 69-86.

Foucault, M. (1983). L'écriture de soi. Corps écrit, 5, 3-23.

Levrero, M. (2005). La novela luminosa. Montevideo: Alfaguara.

Ortiz, M. (2000). Cuadernos de lengua y literatura. Volumen I. Bahía Blanca: Editorial Vox. (2013). Cuadernos de lengua y literatura. Volúmenes V, VI y VII. Buenos Aires: Eterna Cadencia. 
(2014). Cuadernos de lengua y literatura. Volumen VIII. Conectores temporales. Buenos Aires: Eterna Cadencia.

Porrúa, A. (2014). Irrupción y metamorfosis: la imagen en la poesía de Mario Ortiz. Para una crítica poética. Orbis Tertius, XIX (20), 1-7. https://www.orbistertius.unlp.edu.ar/article/view/OTv19n20ao1/6261

Wilson, M. (2013). Leñador. Ruinas continentales. Buenos Aires: Fiordo.

(2014). Wittgenstein y el sentido tácito de las cosas. Santiago de Chile: orjikh editores.

(2017). «Leñador no es una novela sobre la naturaleza, sino sobre el lenguaje», entrevista de Joel

Vargas, ArteZeta. http://artezeta.com.ar/mike-wilson-lenador-no-es-una-novela-sobre-la-naturaleza-

sino-sobre-el-lenguaje/ 